\section{(6) OPEN ACCESS}

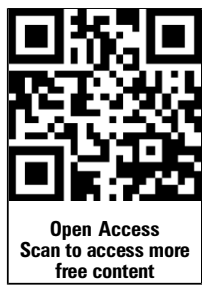

Handling editor Tore K Kvien

- Additional supplementary files are published online only. To view these files please visit the journal online (http://dx.doi. org/10.1136/annrheumdis2012-201611)

${ }^{1}$ Section of Musculoskeletal Disease, University of Leeds \& NIHR Leeds Musculoskeletal Biomedical Research Unit, Leeds, UK

${ }^{2}$ Cliniques Universitaires Saint Luc, Université Catholique de Louvain, Brussels, Belgium

${ }^{3}$ Schlosspark-Klinik, University

Medicine, Berlin, Germany

${ }^{4}$ Department of Rheumatology and Clinical Immunology,

Charité-Universitatsmedizin,

Berlin, Germany

${ }^{5}$ Department of Clinical Immunology and

Rheumatology, F4-105, Academic Medical Center/

University of Amsterdam,

Amsterdam, The Netherlands

${ }^{6}$ GlaxoSmithKine, Stevenage, UK

${ }^{7}$ Rheumatology Unit,

Department of Medicine,

Karolinska Institute and

Karolinska University Hospital,

Stockholm, Sweden

${ }^{8}$ Spire Sciences LCC,

San Francisco, California, USA

${ }^{9}$ Bristol-Myers Squibb, Rueil-

Malmaison, France

${ }^{10}$ Bristol-Myers Squibb,

Princeton, New Jersey, USA

\section{Correspondence to}

Professor PG Conaghan, Division of Musculoskeletal Disease, Chapel Allerton Hospital, Leeds LS7 4SA, UK; p.conaghan@leeds.ac.uk

Received 29 February 2012 Accepted 19 July 2012 Published Online First 21 August 2012

\title{
Impact of intravenous abatacept on synovitis, osteitis and structural damage in patients with rheumatoid arthritis and an inadequate response to methotrexate: the ASSET randomised controlled trial
}

\author{
Philip G Conaghan, ${ }^{1}$ Patrick Durez, ${ }^{2}$ Rieke E Alten, ${ }^{3}$ Gerd-Rüdiger Burmester, ${ }^{4}$ \\ Paul P Tak, ${ }^{5,6}$ Lars Klareskog, ${ }^{7}$ Anca Irinel Catrina, ${ }^{7}$ Julie DiCarlo, ${ }^{8}$ Corine Gaillez, ${ }^{9}$ \\ Manuela Le Bars, ${ }^{9}$ Xianhuang Zhou, ${ }^{10}$ Charles Peterfy ${ }^{8}$
}

\section{ABSTRACT}

Objectives This randomised, double-blind, placebocontrolled phase Illb study evaluated the impact of abatacept on MRI pathology as a primary outcome in methotrexate (MTX)-refractory patients with rheumatoid arthritis.

Methods Patients received intravenous abatacept ( $10 \mathrm{mg} / \mathrm{kg}$ ) or placebo, on background MTX, for 4 months, followed by an 8-month open-label extension (OLE; all patients received abatacept plus MTX). Patients had 1.5T MRI with intravenous contrast at baseline, Months 4 and 12; wrist synovitis (three locations assessed), and wrist and hand (15 and eight locations assessed, respectively) osteitis and erosion were scored using OMERACT-RAMRIS.

Results 26/27 abatacept- and 23/23 placeborandomised patients completed Month 4 and entered the OLE; 26 and 21 completed Month 12. The primary endpoint was not achieved; mean change (SD) from baseline in synovitis was -0.44 (1.47) for abatacept versus 0.52 (1.38) for placebo ( $p=0.103$ ) at Month 4 . For mean change in synovitis adjusted for baseline score (sensitivity analysis), the difference between groups was $-0.69, p=0.078$. Adjusted mean changes (SE) in osteitis and erosion were $-1.94(0.86)$ and $0.45(0.43)$ for abatacept, and $1.54(0.90)$ and 0.95 (0.45) for placebo. Further MRI improvements were observed up to Month 12 for abatacept and from Months 4 to 12 for placebo-treated patients switched to abatacept at Month 4. Clinical efficacy was shown with abatacept and sustained to Month 12.

Conclusions Despite small patient numbers, MRI detected structural and synovial benefit, sustained to Month 12 in abatacept+MTX-treated patients, and improvements in structural and inflammatory outcomes for placebo + MTX-treated patients following addition of abatacept.

Clinical trial registration Clinicaltrials.gov

NCT00420199.

\section{INTRODUCTION}

Evidence of joint destruction and bone loss in rheumatoid arthritis (RA) $)^{1-4}$ has created the need for reliable tools to accurately control the inflammatory process. MRI visualises bone damage (erosions) with increased sensitivity over conventional radiography and enables detection of synovial inflammation (synovitis) and bone oedema (osteitis). ${ }^{1}{ }^{2} 5$ While early MRI studies used longitudinal observational cohorts to assess disease progression and therapeutic response, ${ }^{5}$ relatively few randomised controlled trials (RCTs) have included this technique as a key outcome. ${ }^{3} 4$ 6-11

In clinical trials with intravenous abatacept-a fully human, recombinant fusion protein selectively modulating the CD80/CD86:CD28 costimulatory signal for full $\mathrm{T}$ cell activation-inhibition of radiographic damage progression was sustained over 5 years in patients with established RA, with an increasing inhibitory effect seen over 2 years in patients with early disease. ${ }^{12-17}$ The present exploratory ASSET (Impact of Intravenous Abatacept on Synovitis, Osteitis and Structural DamagE in Patients with Rheumatoid Arthritis and an Inadequate Response to Methotrexate (MTX): A Randomised Controlled Trial) study aimed to evaluate the effect of abatacept versus placebo on MRI pathology and clinical efficacy and safety.

\section{METHODS}

\section{Study design}

ASSET was a phase IIIb randomised, double-blind (DB), placebo-controlled study of 4 months duration with an 8-month open-label extension (OLE), conducted at 11 medical centres in Europe (May 2007-August 2009). Patients were randomised $1: 1$ to receive abatacept $(\sim 10 \mathrm{mg} / \mathrm{kg}$ according to weight range) or placebo, plus background MTX, for 4 months. Randomisation was by central allocation of a unique number in order of qualification for treatment. Clinicians and patients were blinded; drug preparation professionals were unblinded.

Abatacept or placebo was administered intravenously on Days 1, 15, 29 and every 28 days up to and including Month 4. During the OLE all patients received abatacept every 28 days from Month 5 up to Month 12, plus background MTX. Patients exited early if they missed $>2$ consecutive doses; received high dose oral corticosteroids for $>2$ weeks; or were insufficiently controlled (at investigator discretion). 
The primary endpoint was the difference between groups in mean change from baseline to Month 4 in wrist synovitis score; changes in wrist and hand osteitis and erosion were secondary endpoints. The study (clinicaltrials.gov: NCT00420199) was conducted in accordance with Good Clinical Practice, as defined by the International Conference on Harmonisation, and the ethical principles of the Declaration of Helsinki. Institutional review boards or independent ethics committees approved the protocol, and signed, written informed consent was provided by patients.

During the study, the following amendments to study design occurred. Patients could have moderate or high, instead of high, baseline disease activity, in order to improve the feasibility of the study and reflect the improving standard of RA care, given that MTX failure patients may not reach high disease activity before receiving a biologic. The timeframe during which intra-articular steroid injections were prohibited was reduced from 12 to 3 months prior to screening (initial restriction deemed too conservative).

\section{Patient population}

Patients (aged $\geq 18$ years) had active RA (according to American Rheumatism Association (1987) criteria) $\leq 5$ years' duration. Active RA was defined as either Disease Activity Score 28 (DAS28) based on $\mathrm{C}$ reactive protein $(\mathrm{CRP})>3.2$ or a tender joint count of $\geq 6$, a swollen joint count of $\geq 6$ and a CRP measurement greater than the upper limit of normal. Patients had clinically detectable synovitis of at least the target wrist at screening and Day 1 and, in addition, $\geq 1$ erosion present in the hands/wrists and/or feet (on previous radiographs) or were anticyclic citrullinated peptide (CCP) or rheumatoid factor (RF) positive. Patients had received MTX $\geq 15 \mathrm{mg} /$ week or a maximum tolerated dose ( $\geq 10 \mathrm{mg} /$ week) for $\geq 3$ months prior to Day 1 (stable dose $\geq 28$ days prior to first study dose).

\section{Concomitant medications}

Permitted concomitant medications throughout the 12-month study included stable dose MTX (10-25 mg/week; decreases permitted for toxicity during DB) and a stable, low dose of oral corticosteroids (reduced to equivalent $\leq 10 \mathrm{mg}$ /day prednisolone for 28 days). Intra-articular or intramuscular corticosteroid injections were not permitted from 3 months prior to Day 1 . In the OLE, one intramuscular, intra-articular or high dose oral corticosteroid course (defined as $>10 \mathrm{mg} /$ day equivalent of prednisolone for $\geq 3$ consecutive days) was allowed at the discretion of the investigator until the clinical situation had resolved; no intra-articular injections were permitted for the last month of the OLE.

\section{MRI assessments}

Patients had 1.5 Tesla MRI, T1W-coronal short- $\tau$ inversion recovery $(469 \times 625 \times 3000 \mu \mathrm{m}$ voxels $)$ and fat-suppressed $3 \mathrm{D}$ gradient-echo $(234 \times 625 \times 1500 \mu \mathrm{m}$ voxels $)$ of one hand and wrist (based on clinical involvement) and fat-suppressed $3 \mathrm{D}$ gradient-echo plus intravenous gadolinium contrast of the same wrist - at baseline (Day 1), Month 4 (Day 113) and Month 12 (Day 337). A single expert radiologist, blinded to both treatment assignment and time order, scored all images for synovitis, osteitis and bone erosion according to the OMERACT rheumatoid arthritis MRI score (RAMRIS) method. ${ }^{18}$ Images were checked for technical quality and read by a central facility. Two MRI readings were independently made: (1) baseline and Month 4 timepoints (prespecified analysis of the DB period) and (2) baseline, Month 4 and Month 12 timepoints (OLE analysis). The baseline and Month $4 \mathrm{MRIs}$ were reread at the second reading to maintain reader blinding to timepoint order. Intraclass correlation coefficients for the two readings were 0.87 (synovitis), 0.98 (osteitis) and 0.94 (erosion) for baseline MRI scores; 0.89 (synovitis), 0.96 (osteitis) and 0.94 (erosion) for Month $4 \mathrm{MRI}$ scores; and 0.70 (synovitis), 0.86 (osteitis) and 0.55 (erosion) for change from baseline to Month $4 \mathrm{MRI}$ scores.

The proportions of MRI non-progressors for synovitis, osteitis and erosion were evaluated, defined as patients with MRI score change $<1$ unit from baseline. ${ }^{19}$ For further details on the joints that were assessed by MRI and how scoring was performed, please see the online supplementary appendix.

\section{Clinical efficacy}

Disease activity was assessed at each study visit until Month 6, and then at Months 9 and 12 using DAS28 (composite of four variables: 28 tender joint count, 28 swollen joint count, CRP and patient assessment of disease activity (visual analogue scale)) and Simplified Disease Activity Index (SDAI; CRP). DAS28-defined low disease activity state (LDAS: DAS28 $\leq 3.2$ ) and remission (DAS28<2.6), and SDAI-defined LDAS $(\mathrm{SDAI} \leq 11)$ and remission $(\mathrm{SDAI} \leq 3.3)$ were determined.

\section{Safety}

Adverse events (AEs), serious AEs and AEs of interest, including infections, malignancies and prespecified acute infusional reactions, were assessed in patients who received at least one dose of abatacept. See online supplementary appendix for further details.

\section{Statistics}

A total of 50 randomised patients yielded $\geq 87 \%$ power to detect an improvement of 1.44 units in the primary endpoint between the treatment arms using a non-parametric two-sided Wilcoxon test at the 5\% significance level. Sample size calculation was based on three previous studies. ${ }^{20-22}$

For the primary endpoint, comparisons between groups in mean change in wrist synovitis from baseline to Month 4 (based on first reading of baseline and Month 4 MRIs) were based on non-parametric analysis of covariance (ANCOVA), with the rank score for change from baseline in total wrist synovitis score as dependent variable, treatment group as main effect and rank score for total wrist synovitis score at baseline as additional covariate. The $\mathrm{p}$ value for the comparison, with significance level 0.05, was calculated. As probability plots did not reveal deviations from normality in changes from baseline in wrist synovitis score to Month 4, a post hoc sensitivity analysis of the primary endpoint was performed using a parametric ANCOVA, allowing for estimation of the adjusted mean difference between treatment groups. In this sensitivity analysis, change from baseline was the dependent variable, treatment group was the main effect and baseline value an additional covariate.

Adjusted mean changes in synovitis, osteitis and erosion scores from baseline to Month 4, from baseline to Month 12, and from Month 4 to Month 12 were calculated. Adjustment was based on an ANCOVA model with treatment as factor and baseline value as covariate; no between-group comparisons were made. No formal statistical testing was applied to any of the clinical efficacy outcome analyses.

MRI scores and clinical efficacy up to Month 4 are presented for the modified intent-to-treat population, which included all patients randomised and treated with data available at baseline 
and visit of interest (as-observed). Results up to Month 12 (OLE) are presented for patients treated in the OLE with data available at baseline and visit of interest (as-observed).

\section{RESULTS}

\section{Patient disposition and baseline demographics}

Of 50 randomised and treated patients (abatacept $(n=27)$ and placebo $(n=23)$ ), one (abatacept group) discontinued the DB period due to no longer meeting study criteria (hyperparathyroidism). Of the 49 patients who entered the OLE, 47 (95.9\%) completed the study. Two patients, both originally randomised to placebo, discontinued the OLE (see online supplementary figure S1).

Baseline disease characteristics for patients randomised and treated in the $\mathrm{DB}$ period were generally similar between groups, although more patients in the placebo versus abatacept group were RF or anti-CCP positive (table 1) and baseline synovitis and erosion scores were higher in the abatacept group (figure 1A).

\section{Concomitant medications and drug exposure}

At randomisation, concomitant medications were comparable between groups (table 1), and use remained relatively stable throughout DB treatment. During the OLE, all patients continued to receive MTX; $18(69.2 \%)$ and $15(65.2 \%)$ patients in the original abatacept group and the original placebo group, respectively, received low dose corticosteroids ( $\leq 10 \mathrm{mg}$ prednisolone equivalent: mean dose: 3.7 and $3.1 \mathrm{mg} /$ day, respectively).

Table 1 Baseline demographic and clinical characteristics for randomised and treated patients

\begin{tabular}{|c|c|c|}
\hline & $\begin{array}{l}\text { Abatacept }+ \text { MTX } \\
(\mathrm{n}=27)\end{array}$ & $\begin{array}{l}\text { Placebo+ MTX } \\
(\mathrm{n}=23)\end{array}$ \\
\hline Age (years) & $51.7 \pm 11.2$ & $52.5 \pm 11.5$ \\
\hline Female, $\mathrm{n}(\%)$ & $16(59.3)$ & $16(69.6)$ \\
\hline Caucasian, n (\%) & $26(96.3)$ & $19(82.6)$ \\
\hline Duration of RA (months) & $25.7 \pm 18.0$ & $28.2 \pm 17.0$ \\
\hline Tender joints, $\mathrm{n}$ & $12.9 \pm 7.1$ & $13.3 \pm 7.2$ \\
\hline Swollen joints, $n$ & $11.3 \pm 6.6$ & $8.5 \pm 4.1$ \\
\hline $\begin{array}{l}\text { Patient global assessment, VAS } \\
100 \mathrm{~mm}\end{array}$ & $50.9 \pm 24.7$ & $56.6 \pm 24.4$ \\
\hline $\begin{array}{l}\text { Physician global assessment, VAS } \\
100 \mathrm{~mm}\end{array}$ & $51.5 \pm 18.7$ & $57.4 \pm 15.1$ \\
\hline Positive RF status, $\mathrm{n}(\%)^{*}$ & $15(55.6)$ & $19(82.6)$ \\
\hline Positive anti-CCP2 status, $\mathrm{n}(\%)^{*}$ & $13(48.1)$ & $17(73.9)$ \\
\hline DAS28 (CRP) & $5.3 \pm 1.1$ & $5.3 \pm 0.9$ \\
\hline $\mathrm{CRP}(\mathrm{mg} / \mathrm{l})$ & $13.6 \pm 17.4$ & $16.6 \pm 16.8$ \\
\hline CDAl & $34.4 \pm 15.3$ & $33.2 \pm 10.3$ \\
\hline SDAI (CRP) & $35.8 \pm 16.1$ & $34.9 \pm 10.8$ \\
\hline \multicolumn{3}{|c|}{ Concomitant medications at baseline, $\mathrm{n}(\%)$} \\
\hline MTX & $23(100)$ & $27(100)$ \\
\hline $\mathrm{MTX}$ dose, mean $\pm \mathrm{SD} \mathrm{mg} /$ week & $16.9 \pm 4.6$ & $17.3 \pm 4.2$ \\
\hline $\begin{array}{l}\text { Oral and/or injectable } \\
\text { corticosteroids }\end{array}$ & $19(70.4)$ & $14(60.9)$ \\
\hline Low dose oral corticosteroids & $16(59.3)$ & $12(52.2)$ \\
\hline $\begin{array}{l}\text { Oral dose of corticosteroids, mean } \\
\pm \mathrm{SD}\end{array}$ & $3.9 \pm 3.51$ & $3.0 \pm 3.72$ \\
\hline NSAIDs & $22(81.5)$ & $20(87.0)$ \\
\hline
\end{tabular}

Values are means $\pm S D$ unless stated otherwise.

*Per the inclusion criteria, if patients were not RF or anti-CCP2 positive, they had to have radiographic evidence of erosion.

CCP, cyclic citrullinated protein; CDAl, Clinical Disease Activity Index; CRP, C reactive protein; DAS28, Disease Activity Score 28; MTX, methotrexate; NSAIDs, non-steroidal anti-inflammatory drugs; RA, rheumatoid arthritis; RF, rheumatoid factor; SDAl, Simplified Disease Activity Index; VAS, visual analogue scale.
One patient received more than one course of high dose corticosteroids and one patient received more than two intra-articular steroid injections (both original placebo group). The mean (SD) total duration of abatacept exposure across the $\mathrm{DB}$ and OLE was $13.2(0.20)$ months in the original abatacept group and 8.3 (0.84) months in the original placebo group switched to abatacept at Month 4.

\section{MRI assessments}

Primary endpoint: Month 4 (first reading)

Mean MRI scores at baseline and Month 4, according to the first MRI reading, are shown in figure $1 \mathrm{~A}$. From baseline to Month 4, reduction in wrist synovitis score (primary endpoint) was seen for the abatacept group (mean change (SD): -0.44 (1.47), $n=25$ ) compared with worsening of wrist synovitis for the placebo group (mean change (SD): 0.52 (1.38), $n=23$ ), but the difference between treatment groups was not significant $(p=0.103)$.

Sensitivity analysis of primary endpoint: Month 4 (first reading) The sensitivity analysis adjusted for baseline synovitis score using a parametric ANCOVA. In this analysis, mean change (SE) in synovitis was $-0.31(0.26)$ for abatacept versus 0.38 (0.27) for placebo (figure 1A). Difference between treatment groups in adjusted mean synovitis score change approached significance $(-0.69$ (95\% CI -1.45 to 0.08$) ; p=0.078)$.

Adjusted mean change in osteitis and erosion: Month 4 (first reading) A greater reduction in adjusted mean (SE) osteitis score from baseline to Month 4 was observed in the abatacept $(n=25)$ versus placebo $(n=23)$ group: $-1.94(0.86)$ versus 1.54 (0.90), respectively (figure $1 \mathrm{~A}$ ). Erosion progression was also reduced in the abatacept versus placebo group at Month 4 with adjusted mean change (SE) from baseline in erosion scores of $0.45(0.43)$ versus $0.95(0.45)$, respectively (figure $1 \mathrm{~A}$ ).

\section{Month 4 (second reading) MRI outcomes}

Data from the second MRI reading (baseline and Month 4 were reread at Month 12; figure $1 \mathrm{~B}-\mathrm{D}$, left-hand panels) were generally consistent with the MRI data from the first reading.

\section{MRI analysis: Month 12}

In the original abatacept group, further improvements in wrist synovitis and wrist and hand osteitis were seen from Months 4 to 12 (figure $1 \mathrm{~B}, \mathrm{C}$; middle and right-hand panels). In the original placebo group, reductions in synovitis and osteitis were seen after addition of abatacept at Month 4, and by Month 12 the changes from baseline in synovitis and osteitis were similar to those seen in the original abatacept group. Reduced progression of erosion was seen in the original abatacept group from Month 4 to Month 12 with continued treatment (figure 1D; middle and right-hand panels). Erosion score was also reduced in the original placebo group following addition of abatacept at Month 4, although the extent of this reduction was not as great as that seen in the original abatacept group by Month 12 .

MRI non-progressors: Months 4 and 12

A higher proportion of patients in the abatacept group demonstrated non-progression of synovitis and osteitis at Month 4 compared with the placebo group (figure 2; left-hand panels). At Month 12, the proportions of MRI non-progressors for each outcome in the original placebo group switched to abatacept were generally similar to those in the original abatacept group (figure 2; right-hand panels). 
A)

\begin{tabular}{|l|c|c|}
\hline & $\begin{array}{c}\text { Abatacept + MTX } \\
(\mathbf{n = 2 5 )}\end{array}$ & $\begin{array}{c}\text { Placebo + MTX } \\
(\mathbf{n = 2 3 )}\end{array}$ \\
\hline Baseline mean scores (SD) \\
\hline Synovitis (wrists) & $4.48(2.10)$ & $3.52(2.43)$ \\
\hline Erosion (wrist and hand) & $12.60(9.41)$ & $9.65(10.11)$ \\
\hline Osteitis (wrist and hand) & $7.72(7.04)$ & $8.00(9.72)$ \\
\hline Month 4 mean scores (SD) & \\
\hline Synovitis (wrists) & $4.04(1.57)$ & $4.04(2.48)$ \\
\hline Erosion (wrist and hand) & $13.00(9.39)$ & $10.65(9.97)$ \\
\hline Osteitis (wrist and hand) & $5.80(5.31)$ & $9.52(10.88)$ \\
\hline Adjusted mean change from baseline to Month 4 (SE) \\
\hline $\begin{array}{l}\text { Synovitis (wrists; } \\
\text { sensitivity analysis) }\end{array}$ & $-0.31(0.26)$ & $0.38(0.27)$ \\
\hline Erosion (wrist and hand) & $0.45(0.43)$ & $0.95(0.45)$ \\
\hline Osteitis (wrist and hand) & $-1.94(0.86)$ & $1.54(0.90)$ \\
\hline Data are for the initial reading of the Month 4 MRIs, for patients with MRIs available. \\
\hline
\end{tabular}

C)

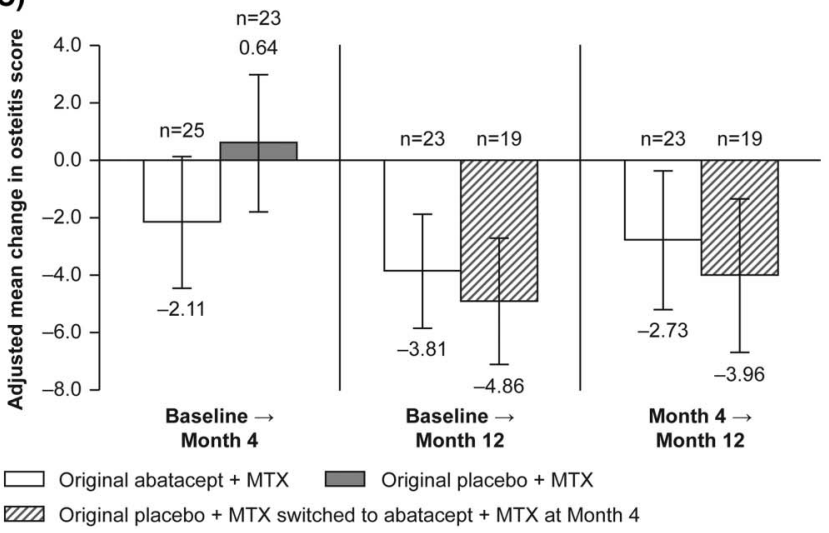

B)

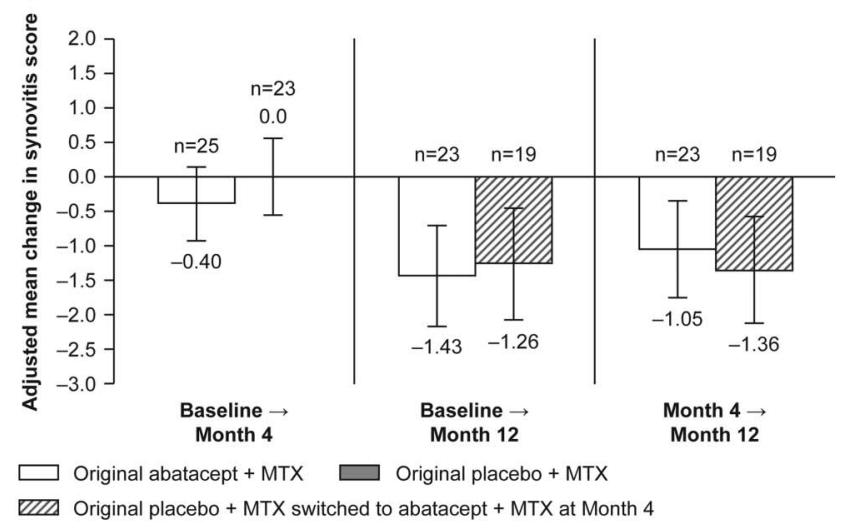

D)

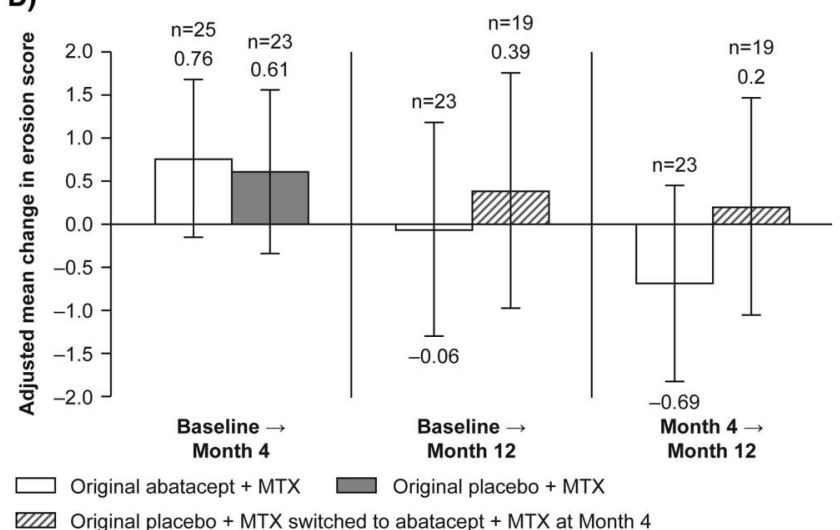

Figure 1 (A) Mean baseline and Month 4 MRI scores based on the first MRI reading and adjusted mean changes from baseline in (B) synovitis, (C) osteitis and (D) erosion scores based on the second MRI reading. Treatment groups represent treatment received in the DB period. Data are presented for all patients who had MRIs available at the visits of interest (as-observed analysis); for the analyses presented in A, data are based on MRIs read at Month 4, and for the analyses presented in (B-D), data are based on MRIs read at Month 12 (baseline and Month 4 MRIs were reread at this timepoint); patients with MRI outside of Days 92-134 were excluded from the Day 113 (Month 4) analysis, and with MRI >4 weeks prior to or after Day 337 were excluded from the Month $12 \mathrm{MRI}$ analysis. Adjustment (B-D) is based on ANCOVA model with treatment as factor and baseline value as covariate. (B-D) Error bars represent $95 \% \mathrm{Cl}$ of the adjusted mean change. Synovitis was assessed only in the wrist (three regions), whereas osteitis and erosion were assessed in the wrist and MCP joints (23 sites: 15 sites in wrist, plus eight in the hand). ANCOVA, analysis of covariance; DB, double-blind; MCP, metacarpophalangeal; MTX, methotrexate.

\section{Disease activity assessments}

Mean reductions (95\% CI) from baseline to Month 4 and Month 12 in DAS28 (CRP) and SDAI are shown in online supplementary figure S2. A higher proportion of patients from the original abatacept group reached remission and LDAS (DAS28- and SDAI-defined) at Month 12 than at Month 4 (figure $3 \mathrm{~A}$ ). At Month 12, the proportion of patients reaching remission and LDAS according to both DAS28 and SDAI criteria remained greater in the original abatacept group than in the original placebo group (figure 3 ).

A post hoc analysis examined the relationship between disease activity at Month 4 and MRI scores at Month 12 in patients treated in the OLE who were originally randomised to abatacept (table 2). Greater reductions in erosion progression and synovitis score at Month 12 were seen for patients with lower versus higher disease activity at Month 4 . Osteitis score at Month 12 was reduced regardless of Month 4 disease activity.

\section{Safety}

A summary of AEs is reported in table 3 and in online supplementary appendix. Most AEs were considered mild or moderate in intensity, and none resulted in withdrawal.

\section{DISCUSSION}

In the phase IIIb, exploratory, ASSET study, intravenous abatacept plus MTX was associated with reductions in synovitis and osteitis and less progression of erosion, compared with placebo plus MTX; increased proportions of abatacept-treated patients experienced non-progression of synovitis and osteitis after 4 months compared with patients receiving placebo plus MTX. A persistent beneficial effect on osteitis and synovitis was observed in patients who remained on abatacept over 12 months, with inhibition of erosion progression also seen. Following addition of abatacept, patients initially randomised to placebo achieved incremental reductions in synovitis and osteitis by Month 12 to levels similar to those seen in patients who had continuously received abatacept. These patients also showed reduced progression in erosion score after initiating abatacept.

MRI assessment of abatacept-treated patients has previously been reported in the ADJUST trial in MTX-naive patients with very early or undifferentiated inflammatory arthritis, and in patients with psoriatic arthritis. ${ }^{23} 24$ The improvements in MRI synovitis, osteitis and erosion progression seen here with abatacept plus MTX over 12 months are consistent with 


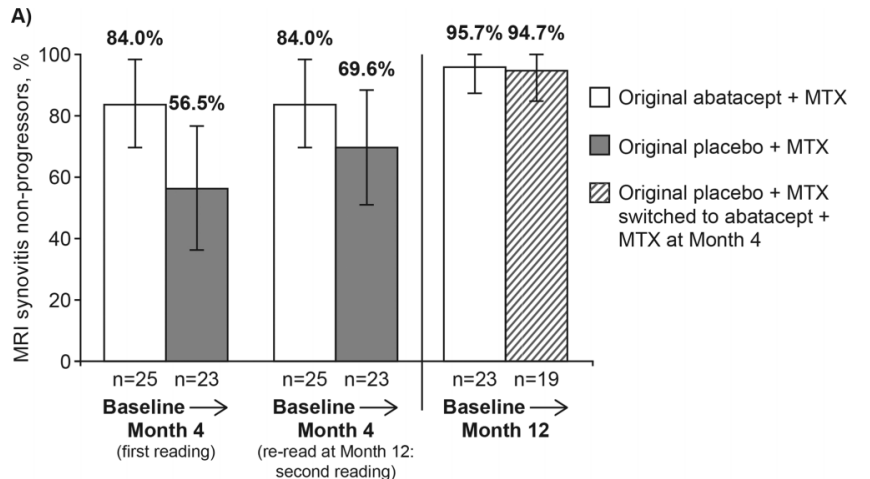

A)
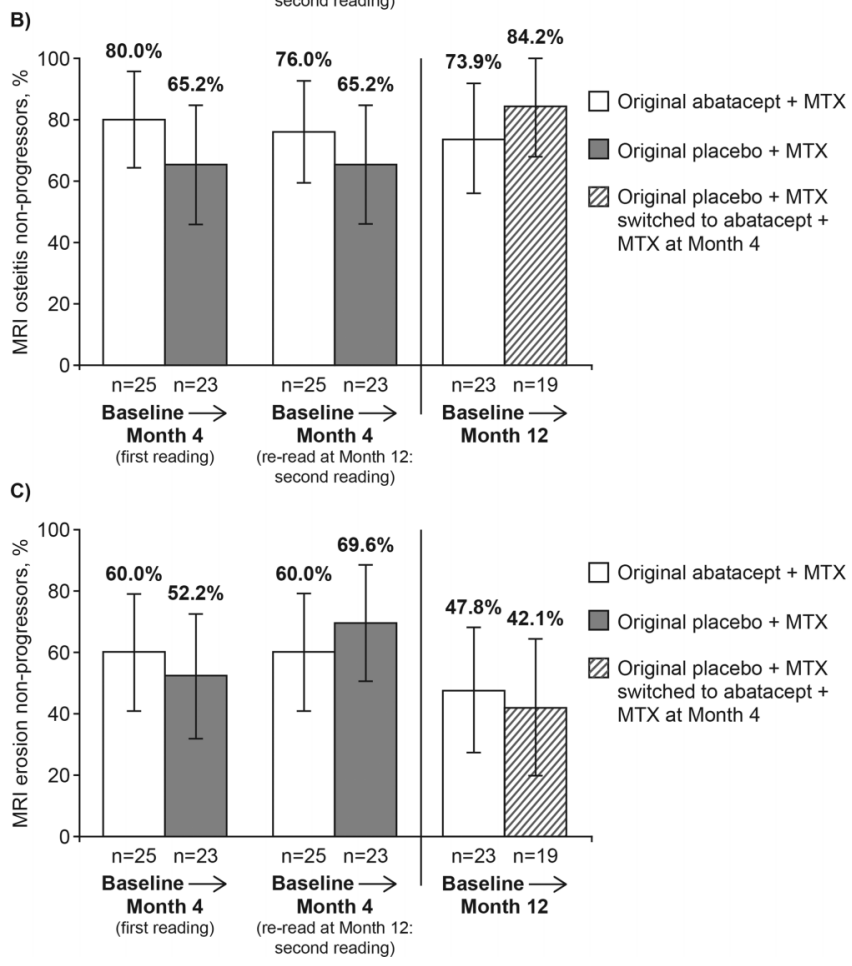

Figure 2 MRI non-progressors at Month 4 and Month 12 in (A) synovitis score, (B) osteitis score and (C) erosion score. Treatment groups represent treatment received in the DB period. Data are presented for all patients who had MRls available at the visits of interest (as-observed analysis); patients with MRI outside of Days 92-134 were excluded from the Day 113 (Month 4) analysis, and with MRI $>4$ weeks prior to or after Day 337 were excluded from the Month $12 \mathrm{MRI}$ analysis. Non-progressors defined by mean change from baseline in MRI score <1 RAMRIS unit. Error bars represent $95 \% \mathrm{Cl}$. Synovitis was assessed only in the wrist, whereas osteitis and erosion were assessed in the wrist and MCP joints. DB, double-blind; MCP, metacarpophalangeal; MTX, methotrexate; RAMRIS, rheumatoid arthritis MRI score.

findings from those trials, and with pharmacodynamic data that suggest abatacept may have a positive effect on bone metabolism through its regulatory effect on osteoclast differentiation and bone resorption. ${ }^{20}$ The degree of local baseline inflammation, both synovitis and osteitis, predicts erosion progression during early disease. ${ }^{25-27}$ Consequently, improving osteitis scores may favourably impact the long-term prognosis of erosion progression. Indeed, inhibition of erosion progression was seen over 12 months of abatacept plus MTX treatment for patients in this study, but was not observed by Month 4 .

The beneficial MRI outcomes seen with abatacept are also consistent with those reported for conventional disease-

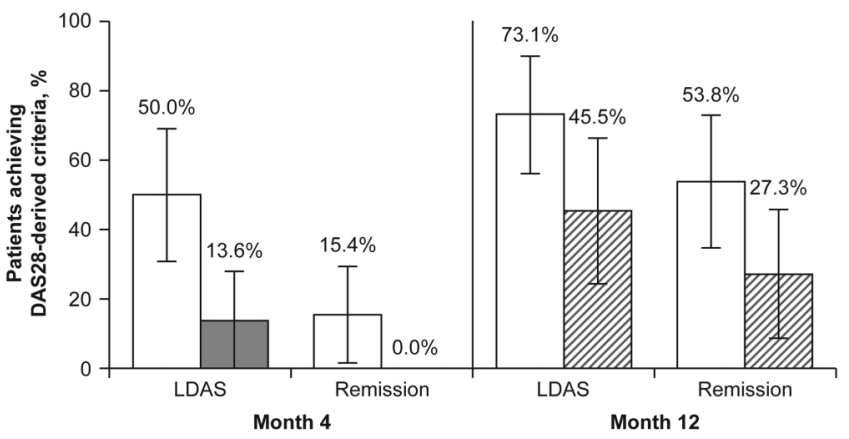

$\square$ Original abatacept $+\operatorname{MTX}(n=26) \quad \square$ Original placebo $+\operatorname{MTX}(n=22)$

WII Original placebo + MTX switched to abatacept + MTX at Month $4(n=22)$

B)

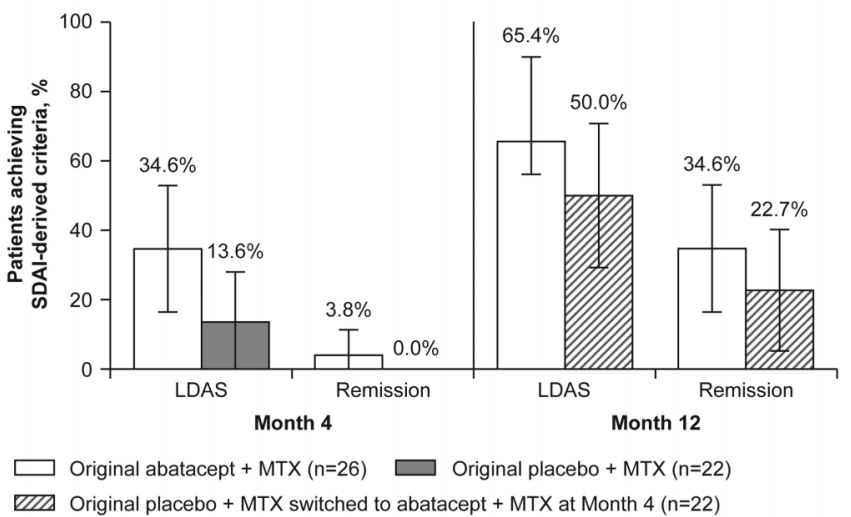

Figure 3 Patients achieving improvements in disease activity according to (A) DAS28-derived criteria and (B) SDAl-derived criteria. Treatment groups represent treatment received in the DB period. DB data (Month 4) are based on the mITT population including all randomised and treated patients with data available at the visits of interest (as-observed analysis); OLE data (Month 12) are based on patients treated in the OLE, with data available at the visit of interest. Error bars represent $95 \% \mathrm{CI}$. CRP, C reactive protein; DAS28, Disease Activity Score 28; DB, double-blind; LDAS, low disease activity state (DAS28 (CRP) $\leq 3.2 ;$ SDAl $\leq 11$ ); mITT, modified intent to treat; MTX, methotrexate; OLE, open-label extension; Remission (DAS28 (CRP) $<2.6$; SDAl $\leq 3.3$ ); SDAl, Simplified Disease Activity Index.

Table 2 Post hoc analysis data

\begin{tabular}{|c|c|c|c|c|}
\hline \multirow[b]{2}{*}{$\begin{array}{l}\text { DAS28 } \\
\text { status at } \\
\text { Month } 4\end{array}$} & \multirow[b]{2}{*}{$\mathbf{N}$} & \multicolumn{3}{|c|}{$\begin{array}{l}\text { Mean change }(95 \% \mathrm{Cl}) \text { in score from baseline to } \\
\text { Month } 12\end{array}$} \\
\hline & & $\begin{array}{l}\text { Synovitis } \\
\text { (wrist) }\end{array}$ & $\begin{array}{l}\text { Osteitis } \\
\text { (wrist and hand) }\end{array}$ & $\begin{array}{l}\text { Erosion } \\
\text { (wrist and hand) }\end{array}$ \\
\hline Remission $(<2.6)^{*}$ & 4 & $\begin{array}{l}-3.00 \\
(-6.90 \text { to } 0.90)\end{array}$ & $\begin{array}{l}-2.75 \\
(-8.47 \text { to } 2.97)\end{array}$ & $\begin{array}{l}-4.75 \\
(-13.11 \text { to } 3.61)\end{array}$ \\
\hline $\operatorname{LDAS}(\leq 3.2)$ & 11 & $\begin{array}{l}-2.64 \\
(-4.15 \text { to }-1.13)\end{array}$ & $\begin{array}{l}-4.09 \\
(-8.44 \text { to } 0.26)\end{array}$ & $\begin{array}{l}-2.18 \\
(-5.12 \text { to } 0.85)\end{array}$ \\
\hline MDAS $(>3.2-5.1)$ & 9 & $\begin{array}{l}-1.00 \\
(-2.84 \text { to } 0.84)\end{array}$ & $\begin{array}{l}-3.22 \\
(-8.17 \text { to } 1.73)\end{array}$ & $\begin{array}{l}1.56 \\
(0.27 \text { to } 2.84)\end{array}$ \\
\hline HDAS $(>5.1)$ & 3 & $\begin{array}{l}0.00 \\
(0.00 \text { to } 0.00)\end{array}$ & $\begin{array}{l}-1.33 \\
(-5.13 \text { to } 2.46)\end{array}$ & $\begin{array}{l}1.33 \\
(-1.54 \text { to } 4.20)\end{array}$ \\
\hline
\end{tabular}

Data are as observed for patients treated in the open-label extension who were originally randomised to abatacept $+\mathrm{MTX}$, who had data available at the visits of interest.

* Subset of LDAS

DAS28, Disease Activity Score 28; HDAS, high disease activity state; LDAS, low disease activity state; MDAS, moderate disease activity state; MTX, methotrexate. 
Table 3 Summary of adverse events during the study

\begin{tabular}{|c|c|c|c|}
\hline \multirow[b]{2}{*}{$\begin{array}{l}\text { Adverse events, number } \\
\text { of patients }(\%)\end{array}$} & \multicolumn{2}{|l|}{ DB period* } & \multirow{2}{*}{$\begin{array}{l}\text { OLE† } \\
\text { Abatacept + MTX } \\
(\mathrm{n}=49)\end{array}$} \\
\hline & $\begin{array}{l}\text { Abatacept + MTX } \\
(\mathrm{n}=27)\end{array}$ & $\begin{array}{l}\text { Placebo+MTX } \\
(n=23)\end{array}$ & \\
\hline Adverse events & $20(74.1)$ & $14(60.9)$ & $41(83.7)$ \\
\hline Related adverse events & $8(29.6)$ & $6(26.1)$ & $24(49.0)$ \\
\hline Serious adverse events & 0 & $2(8.7)$ & $6(12.2)$ \\
\hline Infections & $10(37.0)$ & $6(26.1)$ & $26(53.1)$ \\
\hline Serious infections & 0 & 0 & $1(2.0)$ \\
\hline Malignancies & 0 & 0 & 0 \\
\hline Autoimmune events & 0 & 0 & $1(2.0)$ \\
\hline Acute infusion events & 0 & $4(17.4)$ & $2(4.1)$ \\
\hline Peri-infusional events & $4(14.8)$ & $5(21.7)$ & $6(12.2)$ \\
\hline Deaths & 0 & 0 & 0 \\
\hline
\end{tabular}

*Includes data up to 56 days post the last study drug dose for patients who discontinued or up to the first dose of the OLE for patients who continued.

${ }^{\dagger}$ Events for all patients who received at least one dose of abatacept in the 8-month OLE, up to 56 days post the last dose of open-label abatacept.

DB, double-blind; MTX, methotrexate; OLE, open-label extension.

modifying antirheumatic drugs ${ }^{28}$ and other biologics, with recent RCTs documenting the beneficial effects on MRI assessments of infliximab, adalimumab and golimumab in patients with early RA, ${ }^{4} 1021$ and of denosumab, ${ }^{6}$ fostamatinib, ${ }^{8}$ tocilizumab, ${ }^{29}$ rituximab ${ }^{30}$ and golimumab ${ }^{3}$ in patients with established disease. However, caution must be used when making comparisons across these trials owing to general differences, such as study design, patient populations (particularly different stages of RA) and timepoints evaluated, and MRI-related differences, such as differing magnet field strengths, pulse sequence parameters, the use of contrast agents and the anatomical locations assessed (eg, metacarpophalangeal (MCP) joints and wrists vs wrists alone, as in the current study).

Abatacept treatment improved disease activity over time in this study, consistent with previous abatacept trials, ${ }^{15} 31$ although the proportion of patients achieving treatment targets (based on DAS28 and SDAI) was higher in the current study, probably because these patients had less severe disease at baseline. Patients originally randomised to placebo who switched to abatacept at Month 4 experienced improvements in disease activity by Month 12 that approached those observed in patients continuously treated with abatacept. However, the proportions of patients achieving DAS28 LDAS and DAS28 and SDAI remission at Month 12 suggest that although disease activity improves when patients switch to abatacept, many of them do not reach the low states of disease activity seen in patients who are continuously treated with abatacept.

Control of disease status at Month 4 in the original abatacept group was associated with greater numerical improvements in synovitis and erosion at Month 12 . Reductions in osteitis were seen regardless of the level of disease activity at Month 4. ${ }^{32}$ The disconnect between osteitis and clinical efficacy, where osteitis improved in the context of persistent clinical disease, may be due to the regulatory effect of abatacept on bone, discussed above, or the presence of subclinical disease. Consequently, the reported positive effect on osteitis may result in better long-term structural prognosis regardless of initial clinical efficacy outcomes.

Abatacept was well tolerated by patients, with a high retention rate in both the DB period and OLE. No new safety signals were identified in the OLE relative to the DB period, and overall safety was consistent with previous reports of abatacept. $^{15313334}$
Certain limitations of this study need to be taken into account. Guidance for powering MRI studies remains uncertain, including the number of anatomical sites to be evaluated ${ }^{11}$ and the responsiveness of the scoring system for each pathological feature. This is a direct result of the paucity of published MRI RCTs at the time the study was designed. Therefore, extrapolation of data from previous MRI RCTs to determine the sample size and anatomical sites may have been imprecise and, as such, this study should be considered exploratory. Assessment of synovitis in this study was restricted to the wrist; contrast-enhanced images of the MCP joints were not acquired owing to limitations in MRI examination time. Additionally, osteitis and erosion were not assessed at MCP 1, as per recent modification of RAMRIS. ${ }^{6}{ }^{18}$ Another limitation is that the MRI images were read and scored by only one reader; it has been demonstrated that averaging scores from additional readers can reduce error. ${ }^{11}$ Had two MRI readers been used, and a greater number of patients included in the study, the findings for the primary and secondary outcomes may have been different. Finally, the limited number of patients included in this study, and the difference in proportions of RF and anti-CCP positive patients between groups, should also be taken into account when interpreting the analyses. While small MRI studies are suitable for exploring mechanisms of action, the limited number of patients leads to difficulties in interpreting the relationship between a small number of MRI assessed sites and systemic assessment of disease activity.

Even with the wrist-only assessments of synovitis, abatacept plus MTX was associated with reductions in osteitis, minimal deterioration in erosion and a trend toward reduced MRI synovitis versus placebo plus MTX over 4 months, demonstrating an early effect of abatacept on inflammation and structural damage. With continued treatment, patients initially randomised to abatacept experienced persistent benefit in synovitis and osteitis, with inhibition of erosion progression; patients initially randomised to placebo achieved incremental reductions in MRI assessed inflammation and slowing of erosion progression after switching to abatacept. In conclusion, data from the ASSET study extend current knowledge on the early effect of intravenous abatacept on synovium and bone and confirm its use as an effective and well-tolerated therapeutic option in patients with RA who have previously failed MTX therapy.

\begin{abstract}
Acknowledgements The authors would like to thank Eve Guichard (Medicus International) for her editorial assistance and Coralie Poncet, Keqin Qi (both Bristol-Myers Squibb) and Harry Genant, (UCSF/Synarc) for their expertise and assistance in data analysis and interpretation. The authors and study sponsors would also like to thank the patients and coworkers at the study sites, and the following primary investigators: from Belgium: Yves Boutsen, Catherine Leens, Marie Avaux, Isabelle Focant, Frederic Houssiau, Bernard Lauwerys, Laurent Meric De Bellefon, Adrien Nzeusseu, Maria Stoenoiu and Marie Vanthuyne; from Germany: Karlfried Reinhold Aupperle, Hans Bastian, Robert Biesen, René Dziurla, Eugen Feist, Thomas Haeupl, Annett Jacobi, Bettina Marsmann, Jan Zernicke, Svetlana Djacenko and Christof Pohl; from Spain: Jesus Rodriguez Moreno, Juan De Dios Canete, Victoria Hernandez, Concepcion Moll Tuduri, Africa Muxi and Raimon Sanmarti; from Sweden: Aikaterini Chatzidionysiou, Louise Ekholm, Anders Harju, Aase Hensvold, Peter Matt, Petra Neregard, Hamed Rezaei, Christina Stranger and Anna Vikerfors; from The Netherlands: Mariane Anson, Maartje J.H. Boumans, Marjolein Johanna Helena De Hair, D.M. Gerlag, Krista Klara Maria Glas, Marieke Margriet Jeanine Herenius, Ducli Pocorni and Angelina J.K. Roelse; and from the UK: Paul Emery, Shovik Dass, Helen Maciver, Alison Mcmanus, Sharmin Nizam, Richard Reece, Laura Rhodes, Benazir Saleem, Nita Smeeton, Laszlo Szabo and Edward Vital.
\end{abstract}

Contributors PGC, PD, RA, GRB, PPT, LK, AIC and CP contributed to the acquisition of the data. All authors contributed to the analysis and interpretation of the data and were involved in drafting the article and revising it critically for important intellectual content. This version was approved by all authors for submission/publication.

Funding This study and the editorial support received were funded by Bristol-Myers Squibb. 
Competing interests $\mathrm{P}$ Conaghan has received speaker honoraria, research grants or attended advisory boards for AstraZeneca, Bristol-Myers Squibb, Centocor, Merck, Novartis, Pfizer and Roche. P Durez has received speaker honoraria from Bristol-Myers Squibb, Pfizer, Abbott and Merck. R Alten has received research grants from Bristol-Myers Squibb, Merck Pharma GmbH, Novartis, UCB, Roche, Wyeth Pharmaceuticals and Pfizer, speaker honoraria from Abbott Laboratories, Bristol-Myers Squibb, Horizon Pharma, Novartis and Roche, and consulting fees from Abbott Laboratories, Horizon Pharma, Novartis and Roche. G Burmester has received consulting fees from Abbott Immunology Pharmaceuticals, BMS, Roche, Merck and Pfizer, research grants from Abbott Laboratories, Abbott Immunology Pharmaceuticals, Bristol-Myers Squibb and Roche, and speaker honoraria from Abbott Immunology Pharmaceuticals, Bristol-Myers Squibb and Roche. PP Tak has received consulting fees from Abbott Laboratories, Bristol-Myers Squibb, Genentech, Inc. and Roche, is founder of Arthrogen B.V. Amsterdam, and has received research grants from Bristol-Myers Squibb, Genentech, Inc. and Roche. L Klareskog has received research grants from Centocor Research and Development Inc., Roche, Pfizer, Bristol-Myers Squibb and Abbott. Al Catrina has received grants/research support from: Abbott, Roche and Centocor and speaker honoraria/consultant fees from: Bristol-Myers Squibb, Abbott, Roche and MDS. J DiCarlo is an employee of Spire Sciences and has received consulting fees from AstraZeneca, Bristol-Myers Squibb, Celgene, Eli Lilly, Genentech, Hoffmann-La Roche, Merck, Novartis, Rigel, Roche, Sanofi-Aventis and UCB. C Gaillez, M Le Bars and X Zhou are employees of Bristol-Myers Squibb. C Peterfy has received consulting fees from Abbott Laboratories, Amgen Inc., Astellas Pharma, AstraZeneca, Biogen Idec, Bristol-Myers Squibb, Celgene, Centocor, Inc., Crescendo, Genentech, Hoffmann-La Roche, Inc., Lilly USA, LLC., Merck Pharmaceuticals, Novartis Pharmaceuticals Corporation, Pfizer Inc, Regeneron Pharmaceuticals, Inc., Rigel Pharma, Roche, Samsung Pharmaceutical, UCB, Inc. and Wyeth Pharmaceuticals, and is the founder and CEO of Spire Sciences, LLC.

Ethics approval The laws and regulatory requirements of all countries participating in this study were adhered to. This study was conducted in accordance with Good Clinical Practice, as defined by the International Conference on Harmonisation and in accordance with the ethical principles underlying European Union Directive 2001/20/ EC and the USA Code of Federal Regulations, Title 21, Part 50 (21CFR50). The protocol, amendments and subject-informed consent received appropriate approval by the Institutional Review Board (IRB)/Independent Ethics Committee (IEC) prior to initiation of study at the site. Each IRB/IEC was composed of a review panel that was responsible for ensuring the protection of the rights, safety and well-being of human subjects involved in the clinical investigation and was adequately constituted to provide assurance of that protection. The IRBs/IECs consulted during this study can be provided as a separate document.

Provenance and peer review Not commissioned; externally peer reviewed.

Data sharing statement The IRBs/ECs consulted during this study can be provided as a separate document. No additional unpublished data from this study are available at the time of submission/publication.

Open Access This is an Open Access article distributed in accordance with the Creative Commons Attribution Non Commercial (CC BY-NC 3.0) license, which permits others to distribute, remix, adapt, build upon this work non-commercially, and license their derivative works on different terms, provided the original work is properly cited and the use is non-commercial. See: http://creativecommons.org/licenses/by-nc/3.0/

\section{REFERENCES}

1. McGonagle D, Conaghan PG, O'Connor P, et al. The relationship between synovitis and bone changes in early untreated rheumatoid arthritis: a controlled magnetic resonance imaging study. Arthritis Rheum 1999;42:1706-11.

2. Brown AK, Wakefield RJ, Conaghan PG, et al. New approaches to imaging early inflammatory arthritis. Clin Exp Rheumatol 2004;22(5 Suppl 35):S18-25.

3. Conaghan PG, Emery P, Ostergaard M, et al. Assessment by MRI of inflammation and damage in rheumatoid arthritis patients with methotrexate inadequate response receiving golimumab: results of the GO-FORWARD trial. Ann Rheum Dis 2011;70:1968-74.

4. Ostergaard M, Emery P, Conaghan PG, et al. Significant improvement in synovitis, osteitis, and bone erosion following golimumab and methotrexate combination therapy as compared with methotrexate alone: a magnetic resonance imaging study of 318 methotrexate-naive rheumatoid arthritis patients. Arthritis Rheum 2011;63:3712-22.

5. Freeston JE, Bird P, Conaghan PG. The role of MRI in rheumatoid arthritis: research and clinical issues. Curr Opin Rheumatol 2009;21:95-101.

6. Cohen SB, Dore RK, Lane NE, et al. Denosumab treatment effects on structural damage, bone mineral density, and bone turnover in rheumatoid arthritis: a twelve-month, multicenter, randomized, double-blind, placebo-controlled, phase II clinical trial. Arthritis Rheum 2008;58:1299-309.

7. Durez P, Malghem J, Nzeusseu Toukap A, et al. Treatment of early rheumatoid arthritis: a randomized magnetic resonance imaging study comparing the effects of methotrexate alone, methotrexate in combination with infliximab, and methotrexate in combination with intravenous pulse methylprednisolone. Arthritis Rheum 2007:56:3919-27.
8. Genovese MC, Kavanaugh A, Weinblatt ME, et al. An oral Syk kinase inhibitor in the treatment of rheumatoid arthritis: a three-month randomized, placebo-controlled, phase II study in patients with active rheumatoid arthritis that did not respond to biologic agents. Arthritis Rheum 2011;63:337-45.

9. Peterfy C, Emery P, Tak PP, et al. Rituximab (RTX) plus methotrexate (MTX) prevents bone erosion and joint-space narrowing (JSN) and reduces synovitis, osteitis as shown on MRI: Results from a randomised, placebo-controlled trial in patients (PTS) with rheumatoid arthritis (RA-score). Ann Rheum Dis 2011;70(3 (Suppl.)):152.

10. Peterfy C, Haraoui B, Durez P, et al. Decreased incidence of synovitis, osteitis, and erosion in early RA patients treated with adalimumab plus methotrexate compared to those with methotrexate alone: high-field MRI analysis from OPTIMA (Abstract 123). Arthritis Rheum 2010;62:S51.

11. Peterfy CG, Countryman P, Gabriele A, et al. Magnetic resonance imaging in rheumatoid arthritis clinical trials: emerging patterns based on recent experience. $J$ Rheumatol 2011;38:2023-30.

12. Bathon J, Robles $\mathbf{M}$, Ximenes AC, et al. Sustained disease remission and inhibition of radiographic progression in methotrexate-naive patients with rheumatoid arthritis and poor prognostic factors treated with abatacept: 2-year outcomes. Ann Rheum Dis 2011;70:1949-56.

13. Genant HK, Peterfy C, Westhovens R, et al. Abatacept increases the proportion of patients who remain free from structural damage progression through 5 Years in methotrexate inadequate responders with RA. Ann Rheum Dis 2009;68(Suppl 3):440.

14. Genant HK, Peterfy CG, Westhovens R, et al. Abatacept inhibits progression of structural damage in rheumatoid arthritis: results from the long-term extension of the AIM trial. Ann Rheum Dis 2008;67:1084-9.

15. Kremer JM, Genant HK, Moreland LW, et al. Effects of abatacept in patients with methotrexate-resistant active rheumatoid arthritis: a randomized trial. Ann Intern Med 2006;144:865-76.

16. Kremer JM, Russell AS, Emery P, et al. Long-term safety, efficacy and inhibition of radiographic progression with abatacept treatment in patients with rheumatoid arthritis and an inadequate response to methotrexate: 3 -year results from the AIM trial. Ann Rheum Dis 2011;70:1826-30.

17. Westhovens $\mathbf{R}$, Robles $M$, Ximenes $A C$, et al. Clinical efficacy and safety of abatacept in methotrexate-naive patients with early rheumatoid arthritis and poor prognostic factors. Ann Rheum Dis 2009;68:1870-7.

18. Ostergaard M, Peterfy C, Conaghan P, et al. OMERACT Rheumatoid Arthritis Magnetic Resonance Imaging Studies. Core set of MRI acquisitions, joint pathology definitions, and the OMERACT RA-MRI scoring system. J Rheumatol 2003;30:1385-6.

19. Bruynesteyn K, Boers M, Kostense P, et al. Deciding on progression of joint damage in paired films of individual patients: smallest detectable difference or change. Ann Rheum Dis 2005;64:179-82.

20. Buch MH, Boyle DL, Rosengren S, et al. Mode of action of abatacept in rheumatoid arthritis patients having failed tumour necrosis factor blockade: a histological, gene expression and dynamic magnetic resonance imaging pilot study. Ann Rheum Dis 2009;68:1220-7.

21. Quinn MA, Conaghan PG, O'Connor PJ, et al. Very early treatment with infliximab in addition to methotrexate in early, poor-prognosis rheumatoid arthritis reduces magnetic resonance imaging evidence of synovitis and damage, with sustained benefit after infliximab withdrawal: results from a twelve-month randomized, double-blind, placebo-controlled trial. Arthritis Rheum 2005;52:27-35.

22. Haavardsholm EA, Ostergaard M, Ejbjerg BJ, et al. Reliability and sensitivity to change of the OMERACT rheumatoid arthritis magnetic resonance imaging score in a multireader, longitudinal setting. Arthritis Rheum 2005;52:3860-7.

23. Emery P, Durez P, Dougados M, et al. Impact of T-cell costimulation modulation in patients with undifferentiated inflammatory arthritis or very early rheumatoid arthritis: a clinical and imaging study of abatacept (the ADJUST trial). Ann Rheum Dis 2010;69:510-16.

24. Mease $\mathbf{P}$, Genovese MC, Gladstein $\mathrm{G}$, et al. Abatacept in the treatment of patients with psoriatic arthritis: results of a six-month, multicenter, randomized, double-blind, placebo-controlled, phase II trial. Arthritis Rheum 2011;63:939-48.

25. Palosaari K, Vuotila J, Takalo R, et al. Bone oedema predicts erosive progression on wrist MRI in early RA-a 2-yr observational MRI and NC scintigraphy study. Rheumatology (Oxford) 2006;45:1542-8.

26. Conaghan PG, O'Connor P, McGonagle D, et al. Elucidation of the relationship between synovitis and bone damage: a randomized magnetic resonance imaging study of individual joints in patients with early rheumatoid arthritis. Arthritis Rheum 2003;48:64-71.

27. Boyesen $\mathbf{P}$, Haavardsholm EA, Ostergaard $\mathrm{M}$, et al. MRI in early rheumatoid arthritis: synovitis and bone marrow oedema are independent predictors of subsequent radiographic progression. Ann Rheum Dis 2011;70:428-33.

28. Reece RJ, Kraan MC, Radjenovic A, et al. Comparative assessment of leflunomide and methotrexate for the treatment of rheumatoid arthritis, by dynamic enhanced magnetic resonance imaging. Arthritis Rheum 2002;46:366-72.

29. Troum 0, Peterfy C, Kaine J, et al. Tocilizumab redcues synovitis within 2 weeks and pre-erosive osteitis within 12 weeks in patients with RA: results from a 
multi-site low-field MRI study (Abstract OP0135). Ann Rheum Dis 2010:69 (Suppl 3):98.

30. Peterfy C, Emery P, Tak PP, et al. (OP0246) Rituximab (RTX) plus methotrexate (MTX) prevents bone erosion and joint-space narrowing (JSN) and reduces synovitis, osteitis as shown on MRI: Results from a randomised, placebo-controlled trial in patients (PTS) with rheumatoid arthritis (RA-score). Ann Rheum Dis 2011;70(Suppl 3):152.

31. Schiff M, Keiserman M, Codding C, et al. Efficacy and safety of abatacept or infliximab vs placebo in ATTEST: a phase III, multi-centre, randomised, double-blind, placebo-controlled study in patients with rheumatoid arthritis and an inadequate response to methotrexate. Ann Rheum Dis 2008;67:1096-103.
32. Durez P, Alten R, Tak PP, et al. The relationship between MRI outcomes and clinical efficacy in abatacept-treated patients with rheumatoid arthritis (RA) and an inadequate response to methotrexate (MTX). Ann Rheum Dis 2011;70(Suppl 3): SAT0284.

33. Hochberg M, Westhovens R, Aranda R, et al. Long-term safety profile of abatacept (Orencia) from the rheumatoid arthritis clinical trial program; integrated analysis of data from 12,132 patient-years of exposure. Arthritis \& Rheumatism 2010;62(10 Suppl):S164-5.

34. Alten R, Kaine J, Keystone E, et al. Safety of Subcutaneous Abatacept in Patients with Rheumatoid Arthritis (RA): Integrated Analysis of Five Clinical Trials up to 4.5 Years. Presented at EULAR, London, 25-28th May 2011. Poster SAT0292 2011. 